Check for updates

Cite this: RSC Adv., 2018, 8, 12684

Received 6th December 2017

Accepted 9th March 2018

DOI: 10.1039/c7ra13065a

rsc.li/rsc-advances

\section{Preparation of a novel polyacrylic acid and chitosan interpenetrating network hydrogel for removal of $\mathrm{U}(\mathrm{vI})$ from aqueous solutions}

\author{
Jiarui He, Fuliang Sun, Fuhao Han, Junjie Gu, Minrui Ou, Wenkai Xu \\ and Xiaoping $\mathrm{Xu}$ (D) *
}

A clean and simple method has been developed for preparation of interpenetrating polymer networks using polyacrylic acid (PAA) and chitosan (CS) for extraction of uranium from polluted water. The peak of Fourier transform infrared spectroscopy (FTIR) occurred at $928 \mathrm{~cm}^{-1}$ indicating combination of uranium and PAA/ CS. The energy dispersive X-ray (EDX) and the scanning electron microscope (SEM) studies illustrated the formation of a crosslinking structure and excellent binding ability of uranium on PAA/CS. The maximum adsorption capacity was $289.6 \mathrm{mg} \mathrm{g}^{-1}$ calculated using the equation of the Langmuir model. The adsorption capacity reached a plateau at $\mathrm{pH} 4$ and the sorption process fits the pseudo-second-order model well. The PAA/CS composite has stability of reuse, with the adsorbent capacity decreasing slowly with increasing usage frequency. The experimental results confirm that the PAA/CS hydrogel could be a novel alternative for highly efficient removal of uranium from wastewater.

\section{Introduction}

Conventional energy sources from the degradation of coal and petroleum cause serious environmental and human health problems. The high speed development of nuclear energy as an alternative means that various radionuclides are being released into the environment from the legacy of mining, nuclear reactors, and activities of nuclear weapons. ${ }^{1}$ The uranium ion is one of the most common contaminating ions, with high radiation and chemical toxicity. Therefore, focus in recent years has been on how to reduce the uranium ion content in drinking water. Although various methods are available to reduce uptake of radioactive elements in various fields, efficient techniques are still required.

There are many physical and chemical methods for removal of uranium from wastewater including instance ion-exchange processes, ${ }^{2}$ solvent extraction, ${ }^{3}$ surface complexation, and adsorption. ${ }^{4-6}$ Adsorption has been used by many plants and enterprises because of its excellent performance, easy operation, low consumption, high efficiency, and environmental friendliness. ${ }^{7-10}$ A variety of materials have been extensively studied for adsorption. Traditional materials for extraction of uranium ions from aqueous solution, such as carbon, ${ }^{11,12}$ zeolite, ${ }^{13}$ clay, ${ }^{14}$ composites,${ }^{15}$ natural polymers, ${ }^{16}$ and synthetic polymers, ${ }^{17}$ have abundant pores or functional groups. Among them, the binding capacity of chitosan is higher than that of commercial adsorbents, it is cheap and rich in nature, so it is of

College of Chemistry, Fuzhou University, Fuzhou, 350108, China. E-mail: xu@fzu.edu. cn great interest to researchers for remediation of metal ions. ${ }^{18,19}$ However, the raw material of particle chitosan is usually difficult to recycle after adsorption reaction. Hydrogel, one of the most widely used polymers, consists of a three-dimensional network of hydrophilic polymers which allows diffusion of solutes into the interior network, and can be prepared using a covalent or a non-covalent approach with different functional groups such as carboxylic acid, hydroxyl and amine groups. ${ }^{18,19}$ PAA hydrogel has a specific adsorption capacity based on the mutual attraction between carboxyl and metal cations, and its synthetic steps are relatively timely, convenient, and flexible. ${ }^{20}$ Compared with chitosan, PAA has a stable and water insoluble structure. Furthermore, the bulk gel prepared from acrylic monomer holds recycle performance, hence research into CS/ PAA composites is desirable.

In this work, a PAA-chitosan interpenetrating network is fabricated for sorption of uranium in potable water. The $\mathrm{pH}$, contact time, and initial concentration were assessed by batch adsorption tests. The adsorption performance and mechanism were investigated by kinetic and isotherm models. PAA/CS composites were reused five times to predict properties of sustainable utilization. The experimental results indicate that the PAA/CS hydrogel has much potential in disposal of sewage.

\section{Experimental}

\subsection{Materials}

Acrylic acid (AA) and methylene-bis-acrylamide (MBA) were purchased from Sinopharm Chemical Reagent Co., Ltd. Chitosan (CS) and sodium hydrogen sulfite (SHS) were provided by 


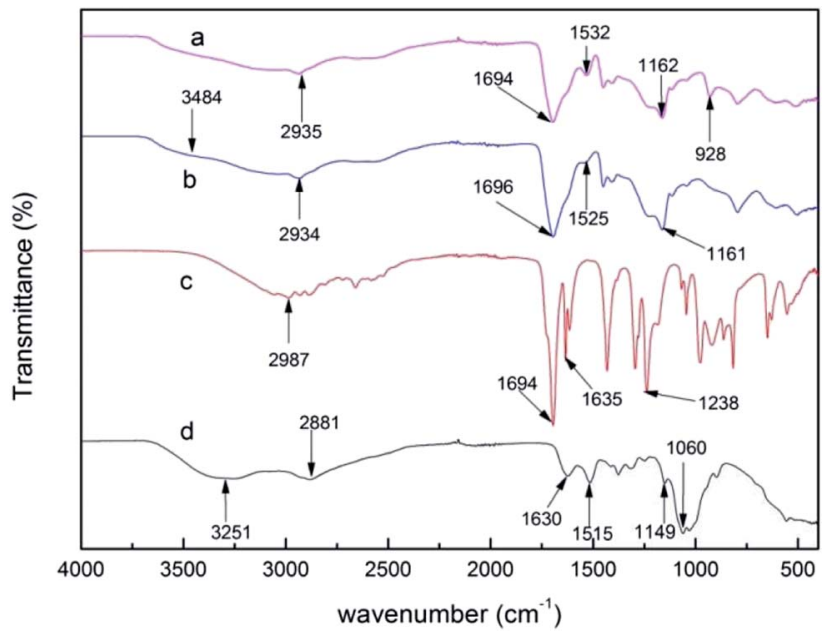

Fig. 1 Fourier transform-infrared (FT-IR) spectra of (a) U-PAA/CS, (b) PAA/CS, (c) AA and (d) CS.

Xilong Chemical Co., Ltd. Ammonium persulfate (APS) was supplied by Shanghai SANGON Biological Engineering Co., Ltd, China. A uranium stock solution $\left(1000 \mathrm{mg} \mathrm{L}^{-1}\right)$ was prepared by adding $\mathrm{UO}_{2}\left(\mathrm{NO}_{3}\right)_{2} \cdot 6 \mathrm{H}_{2} \mathrm{O}$ to deionized water. All chemicals used in this study were of analytical grade.

\subsection{Preparation of PAA/CS}

The chitosan ( $2 \mathrm{~g}$ ) was dissolved in a beaker of acetic acid solution with a mass fraction of $20 \%$ by stirring for about $20 \mathrm{~min}$ at room temperature, and about $0.20 \mathrm{~g}$ APS and $0.20 \mathrm{~g}$ SHS was added to the solution with slow stirring. Then the acrylic monomer $(14 \mathrm{~mL})$ and $0.48 \mathrm{~g}$ MBA were put into a beaker, with ultrasound for 10 minutes. One of the solutions was poured into the other after both solutes were welldistributed. After the hydrogel formed, the product was washed with deionized water several times. Finally, the obtained hydrogel was dried in a vacuum freeze-drying machine for $12 \mathrm{~h}$ and stored in a vacuum drying oven at $55{ }^{\circ} \mathrm{C}$.

\subsection{Instrumentation}

FTIR (Fourier transform infrared spectroscopy) of the samples was analyzed using a FTIR spectrophotometer in the range of 4000-400 $\mathrm{cm}^{-1}$.

SEM (scanning electron microscope) analysis of PAA/CS and PAA/CS after adsorption were recorded using Nova Nano 230 apparatus.

EDX (energy dispersive X-ray) measurements were carried out employing a scanning electron microscope as mentioned before.

\subsection{Adsorption experiments}

Batch adsorption experiments were performed by adding $0.01 \mathrm{~g}$ PAA/CS to a conical flask with $10 \mathrm{~mL}$ standard solution, of concentration $100 \mathrm{mg} \mathrm{L}^{-1}$ diluted by the stock solution and shaking at $150 \mathrm{rpm}, 28{ }^{\circ} \mathrm{C}$. After that, the concentration of supernatant in the system was analyzed by UV-vis spectrophotometer with a wavelength of $650 \mathrm{~nm}$ using Arsenazo-III as the complexing agent.

The $\mathrm{U}(\mathrm{vI})$ ion removal amounts on PAA/CS hydrogel were calculated as follows:

$$
q_{\mathrm{e}}=\frac{C_{0}-C_{\mathrm{e}}}{m} V
$$

where $q_{\mathrm{e}}$ is the adsorption capacity of the PAA/CS $\left(\mathrm{mg} \mathrm{g}^{-1}\right), C_{0}$ is the initial concentration of $\mathrm{U}(\mathrm{vI})$ ions before adsorption $(\mathrm{mg}$

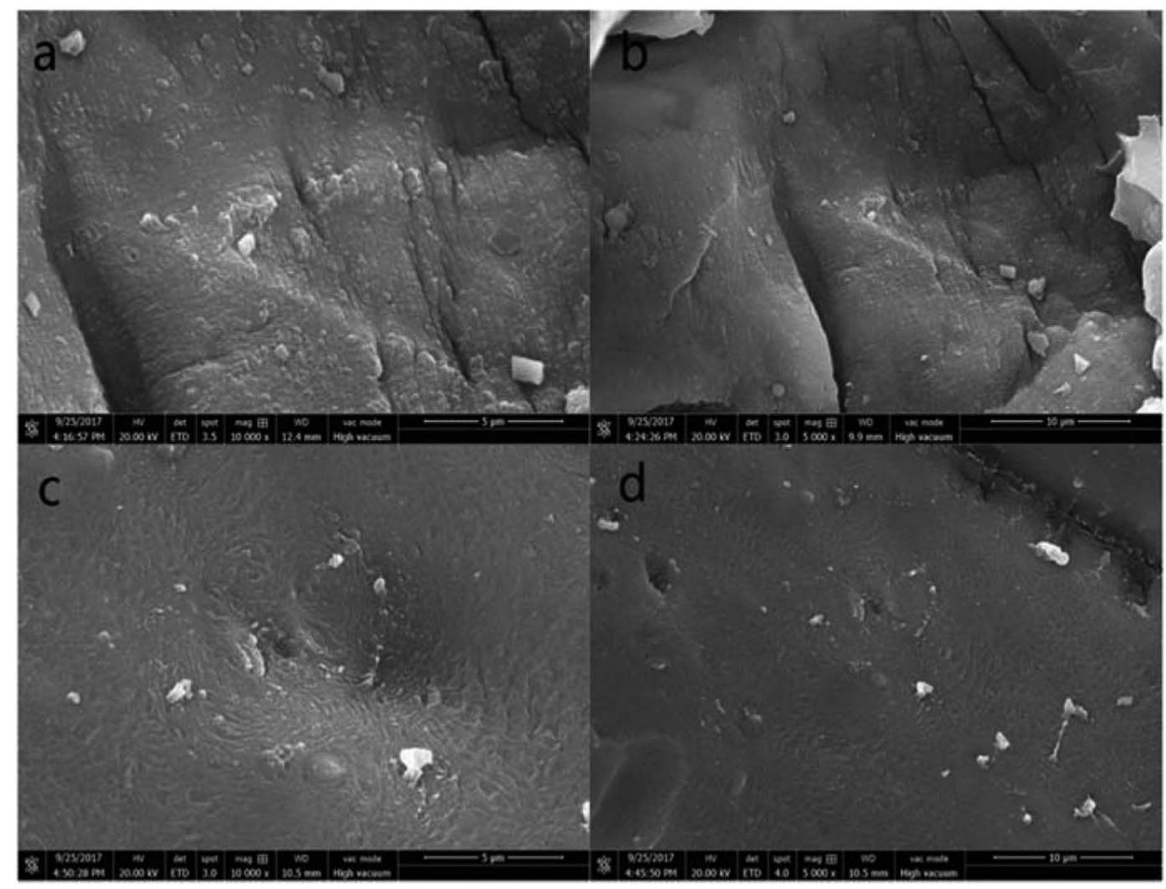

Fig. 2 SEM images of PAA/CS. (a) and (b) Before adsorption, (c) and (d) after adsorption. 

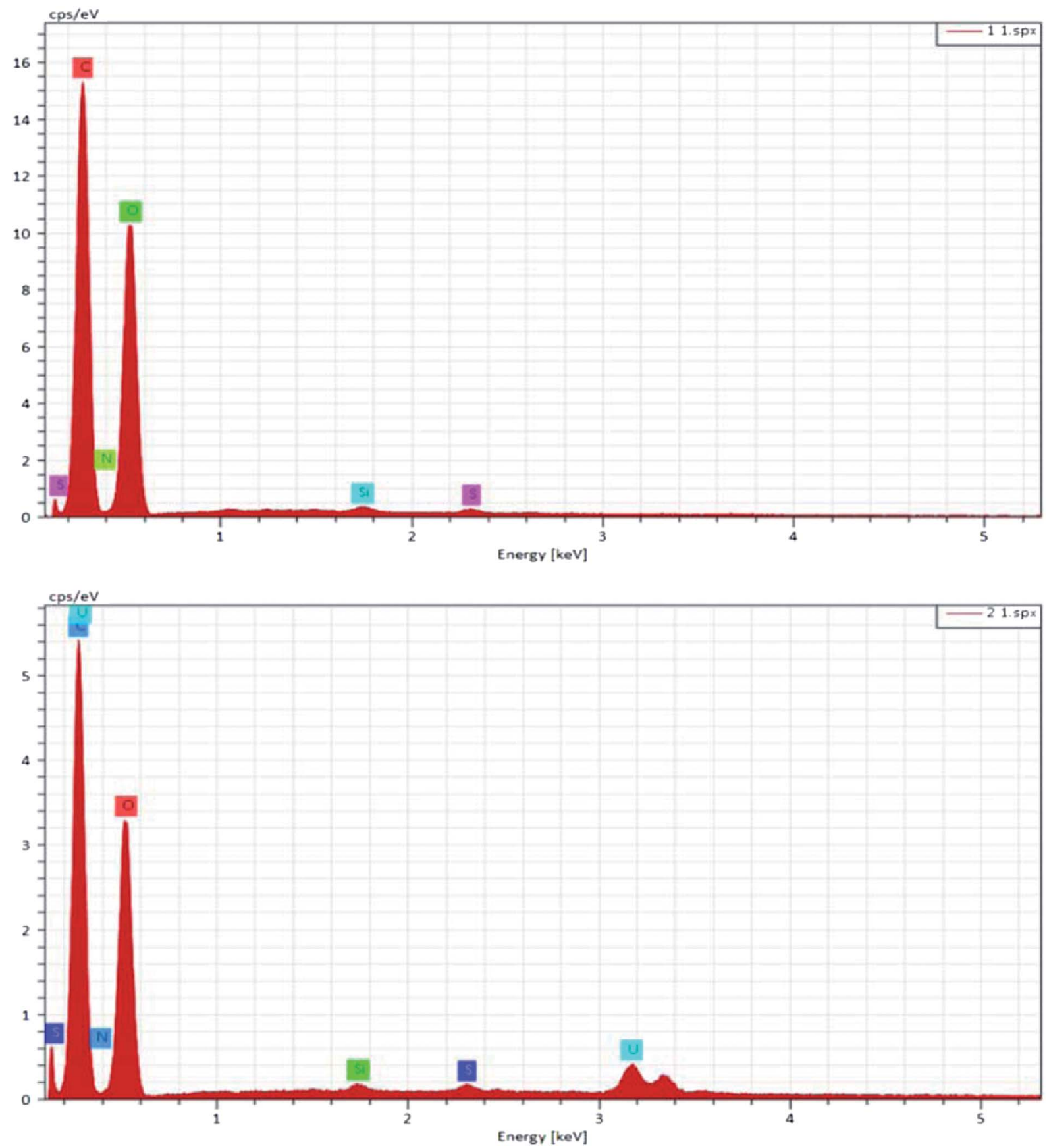

Fig. 3 EDX spectra of PAA/CS. Before adsorption and after adsorption.

$\left.\mathrm{L}^{-1}\right), C_{\mathrm{e}}$ is the final concentration of $\mathrm{U}(\mathrm{vI})$ ions after adsorption $\left(\mathrm{mg} \mathrm{L}^{-1}\right), V$ is the volume of $\mathrm{U}(\mathrm{vI})$ ion solution $(\mathrm{mL})$, and $m$ is the absorber mass supplied $(\mathrm{g})$.

To investigate the effect of $\mathrm{pH}$ on adsorption, the $\mathrm{pH}$ value of solution before adsorption was adjusted to 1-5.5 with the diluted $\mathrm{HNO}_{3}(0.1 \mathrm{M})$ or $\mathrm{NaOH}(0.1 \mathrm{M})$ at initial $\mathrm{U}(\mathrm{vI})$ ions of 50 , 100 , and $150 \mathrm{mg} \mathrm{L}^{-1}$.

To assess the effect of initial ion concentrations on adsorption, the PAA/CS of $0.01 \mathrm{~g}$ was added to several flasks containing $10 \mathrm{~mL}$ solutions in which the initial $\mathrm{U}(\mathrm{vI})$ ions concentrations were $20-500 \mathrm{mg} \mathrm{L}^{-1}$ and $\mathrm{pH} 4.0$ at $28{ }^{\circ} \mathrm{C}$.
The isotherms were studied by adding $0.01 \mathrm{~g}$ PAA/CS in eight equal volume flasks containing $10 \mathrm{~mL} \mathrm{U}(\mathrm{vI})$ ion solution with initial ion concentrations of 20,50,100, 150, 200, 300, 400, and $500 \mathrm{mg} \mathrm{L}{ }^{-1}$, at $28{ }^{\circ} \mathrm{C}$, with shaking for $300 \mathrm{~min}$. The effect of contact time and the adsorption kinetic experiments were conducted using initial uranium concentrations of 50,100, and $150 \mathrm{mg} \mathrm{L}{ }^{-1}$, at $28{ }^{\circ} \mathrm{C}$, with shaking for $350 \mathrm{~min}$. Finally, the supernatants were taken at different time intervals $(10,20,35$, $50,80,110,170,230,290,350 \mathrm{~min})$ and the residual $\mathrm{U}(\mathrm{vI})$ ion concentrations in solution were calculated.

After the adsorption reached equilibrium, the absorbent was soaked in elution solution $\left(0.1 \mathrm{M} \mathrm{HNO}_{3}\right)$ for about $12 \mathrm{~h}$ at room 
temperature and washed with distilled water to neutral. The regenerative adsorbent was reused five times.

\section{Results and discussion}

\subsection{Characterization of PAA/CS}

The infrared spectra of AA, CS, PAA/CS, and PAA/CS after adsorption in the region of $400-4000 \mathrm{~cm}^{-1}$ are depicted in Fig. 1. Strong absorption peaks appeared at $1694 \mathrm{~cm}^{-1}$, which indicated the stretching of the carboxylic group from AA, PAA/ CS, and U-PAA/CS complexes. CS shows characteristic peaks at $3251,1630,1515$, and $1060 \mathrm{~cm}^{-1}$ corresponding to the stretching of $\mathrm{O}-\mathrm{H}$, amide-I, amide-II, and the stretching of -CO-C, respectively. ${ }^{21,22}$ The peak that disappeared at $1635 \mathrm{~cm}^{-1}$ from $-\mathrm{C}=\mathrm{C}-$ is attributed to polymerization of $\mathrm{AA}$ monomer, and the emerging peaks at $1525 \mathrm{~cm}^{-1}$ (amide characteristic absorption bands) are assigned to the addition of CS, confirming the PAA/CS product formed. After adsorption, there was a new peak at $928 \mathrm{~cm}^{-1}$ from the stretching vibration of $\mathrm{O}=\mathrm{U}=$ $\mathrm{O}$, suggesting that uranium ions can be absorbed by PAA/CS composite.

Scanning electron microscopy (SEM) images of PAA/CS and U-PAA/CS are shown in Fig. 2. As depicted in Fig. 2(c) and (d), the overall frame structure of composite was not changed after adsorption, which suggested that the gel after adsorption of uranium was no trail of destruction. The surface of the materials became denser and roughened during the diffusion of $\mathrm{UO}_{2}{ }^{2+}$ in many pores of hydrogels. The surface stripe of the adsorbent changed to a spiral, which could be attributed to the swelling of the uranium solution into the interior of the absorbent. The results showed the PAA/CS hydrogels had a strong binding capacity with $\mathrm{UO}_{2}{ }^{2+}$.

EDX analysis was conducted, and is depicted in Fig. 3. It is worth noting that the absorbent contains three elements, $\mathrm{C}, \mathrm{O}$, and $\mathrm{N}$ (Table 1), and after adherence of uranium onto the surface of PAA/CS, a new peak of $U$ appeared in the EDX spectrum, confirming that the $\mathrm{UO}_{2}{ }^{2+}$ is successfully captured by $\mathrm{PAA} / \mathrm{CS}$.

3.1.1 Effect of initial concentration of the U(Iv) ions. The effects of initial $\mathrm{U}(\mathrm{Iv})$ ions concentrations on the adsorption process by PAA/CS at $28{ }^{\circ} \mathrm{C}$ with $\mathrm{pH}=4$ are presented in Fig. 4 , in which it can be seen that adsorption of U(IV) on PAA/CS increased with increasing concentrations of the $\mathrm{U}(\mathrm{vI})$ ions. This may be because the increase of concentration decreases mass transfer resistance between the solid and liquid phases. ${ }^{23}$ At the same time, with the concentration increased, the particular number of active binding sites determined that adsorption no longer occurred.

3.1.2 Effect of initial $\mathbf{p H}$. The $\mathrm{pH}$ of aqueous solution affects the adsorption process as it can influence interaction

Table 1 Elemental composition of the PAA/CS and U-PAA/CS by EDX

\begin{tabular}{lllll}
\hline Samples & $\mathrm{C}(\%)$ & $\mathrm{N}(\%)$ & $\mathrm{O}(\%)$ & $\mathrm{U}(\%)$ \\
\hline PAA/CS & 54.66 & 5.60 & 39.56 & 0 \\
U-PAA/CS & 51.28 & 4.36 & 43.39 & 0.97
\end{tabular}

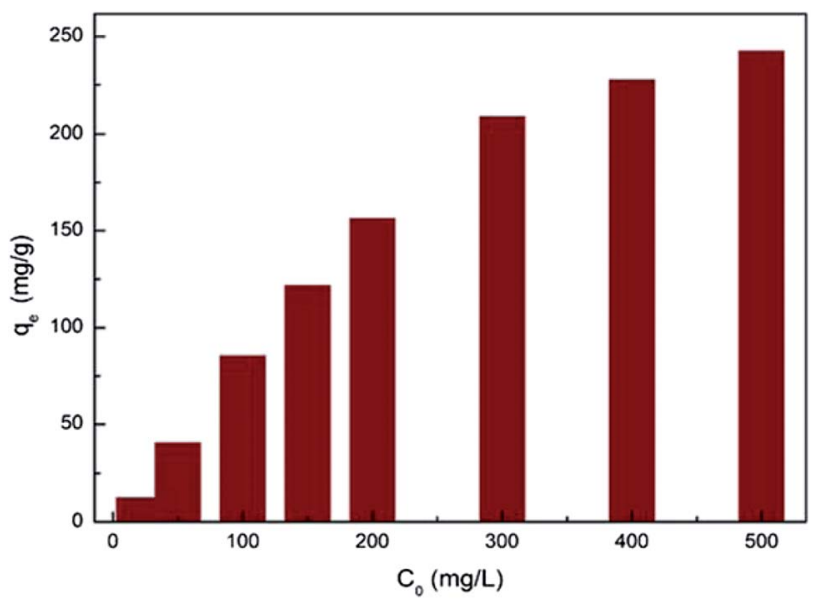

Fig. 4 Effect of initial concentrations (20, 50, 100, 150, 200, 300, 400, $500 \mathrm{mg} \mathrm{L}^{-1}$ ) on $\mathrm{U}(\mathrm{VI})$ removal by PAA/CS hydrogels. (Volume, $10 \mathrm{~mL}$; absorbent dose, $0.01 \mathrm{~g}$; $\mathrm{pH}$ value, 4.0; temperature, $28{ }^{\circ} \mathrm{C}$; rotating speed, $150 \mathrm{rpm})$.

between different ions in the system, and the adsorption of $\mathrm{UO}_{2}{ }^{2+}$ ions depends on distribution of the uranium species in solution. ${ }^{24}$ Fig. 5 shows that the adsorption capacities of PAA/CS enhanced sharply because of deprotonation of the amino groups and carboxyl group with increase of $\mathrm{pH}$ from 2 to 4 , and then the adsorption capacity showed independent on further increasing of $\mathrm{pH}$ and reached a plateau at $\mathrm{pH} 4$, attributed to the fixed amount of $-\mathrm{COO}^{-},-\mathrm{OH}$, and $-\mathrm{NH}_{2}$ on absorber in aqueous solution. The decreased concentration of uranium in the aqueous phase suggests that U(Iv) ions are adsorbed through ion-exchange with hydrogen ions on the binding sites formed by amino groups and through electrostatic attraction with carboxyl groups on PAA/CS hydrogel.

3.1.3 Effect of contact time and kinetic studies. Fig. 6(a) shows the trend of adsorption versus contact time by PAA/CS. The rate of adsorption at the early stage was faster than that at the latter period, and the maximum adsorption capacity was

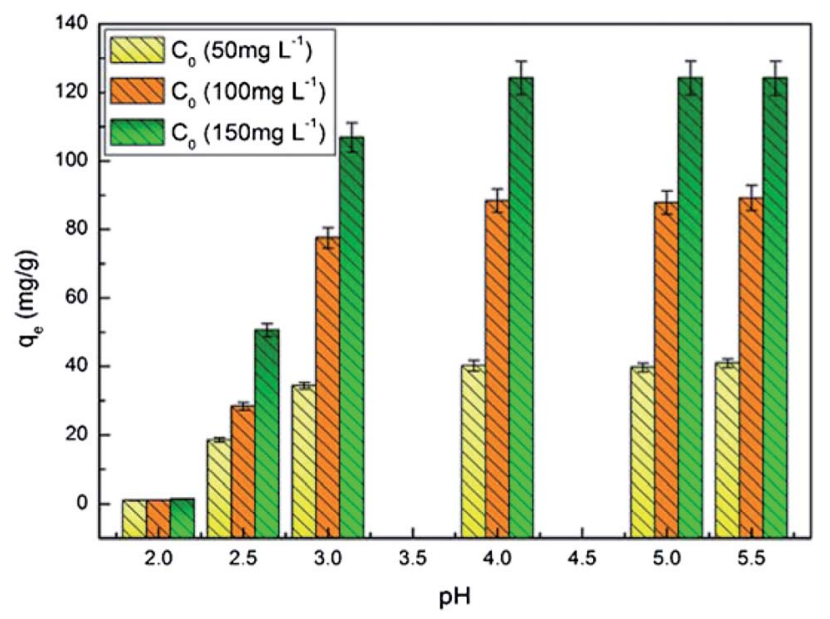

Fig. 5 Effect of contact $\mathrm{pH}$ on $\mathrm{U}(\mathrm{vI})$ adsorption. (Volume, $10 \mathrm{~mL}$; absorbent dose, $0.01 \mathrm{~g}$; initial concentration, 50,100, and $150 \mathrm{mg} \mathrm{L}^{-1}$; $\mathrm{pH}$ value, 4.0; temperature, $28^{\circ} \mathrm{C}$; rotating speed, $150 \mathrm{rpm}$ ). 

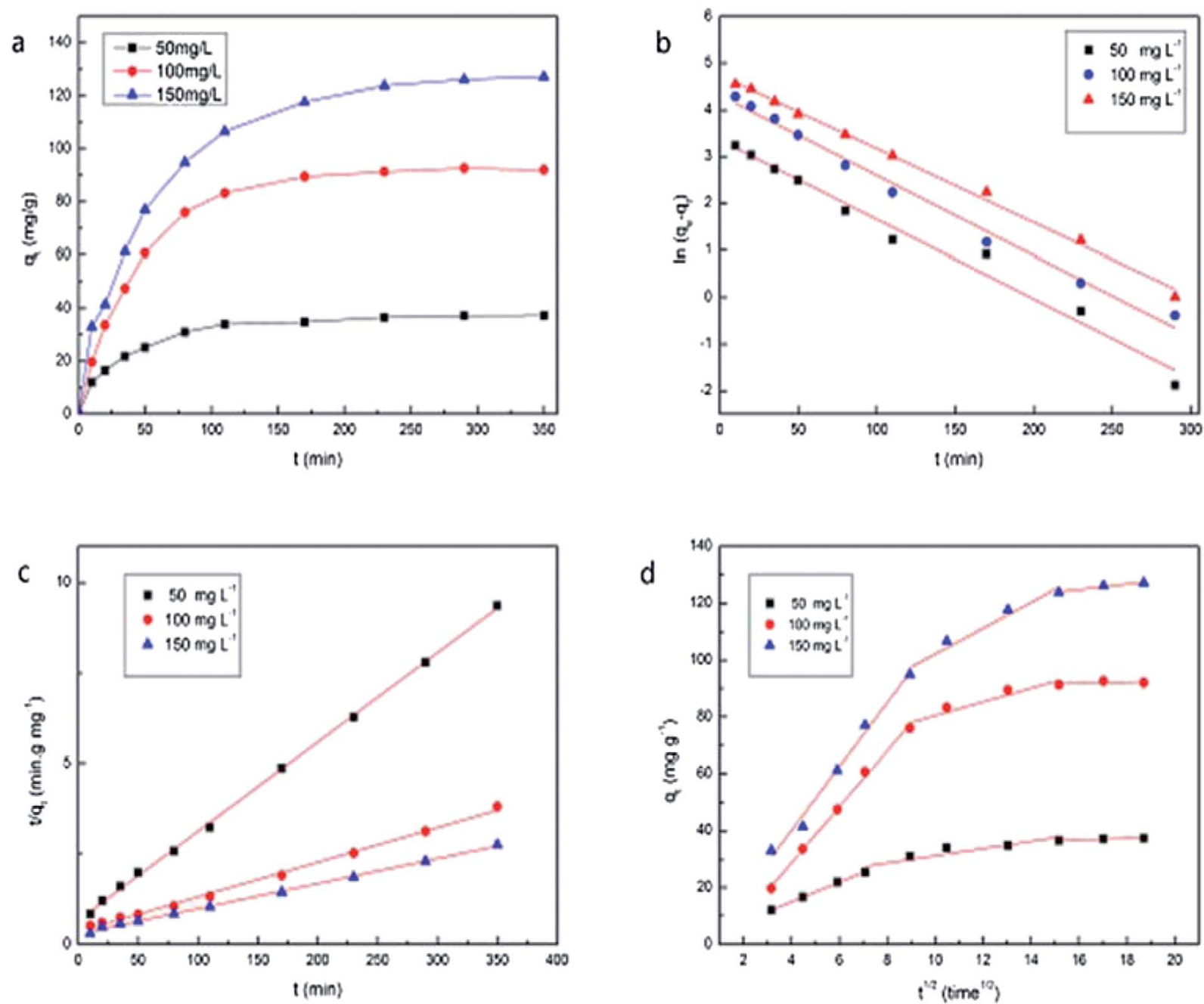

Fig. 6 (a) Effect of contact time on U(v) adsorption; (b) pseudo-first-order and (c) pseudo-second-order sorption kinetics; (c) intraparticle diffusion kinetics of $U(\mathrm{VI})$ onto PAA/CS at various initial concentrations.

obtained at the equilibrium stage $(250 \mathrm{~min})$. To allow most of the binding sites to be occupied by uranium ions and the adsorption end-point to be at a stable stage, 350 min was selected as the reaction time in subsequent experiments.

Kinetic studies revealed the dynamic process and the mechanism of sorption. Pseudo-first-order, pseudo-secondorder kinetic models and intra-particle diffusion model are mainly used to fit the experimental data.

The pseudo-first-order model is expressed in the following equation:

$$
\ln \left(q_{\mathrm{e}}-q_{\mathrm{t}}\right)=\ln q_{\mathrm{e}}-k_{1} t
$$

The pseudo-second-order model is expressed in the following equation:

$$
\frac{t}{q_{t}}=\frac{1}{k_{2} q_{\mathrm{e}}^{2}}+\frac{t}{q_{\mathrm{e}}}
$$

where $q_{\mathrm{e}}$ and $q_{t}$ represent the absorbed amounts on PAA/CS at equilibrium and time $t(\mathrm{~min})$, respectively. $k_{1}$ and $k_{2}\left(\mathrm{~min}^{-1}\right)$ are the rate constant of the pseudo-first-order model and second-order kinetic equation. $t$ is the contact time of the adsorption process.

In addition, the model of intra-particle diffusion can be expressed as:

$$
q_{t}=k_{\mathrm{i}} t^{1 / 2}+C
$$

where $k_{\mathrm{i}}\left(\mathrm{mg} \mathrm{g}^{-1} \min ^{-1 / 2}\right)$ is the rate constant of intra-particle diffusion, and $C$ is thickness of the boundary layer.

As shown in Table 2, the $k_{1}, k_{2}$, and $q_{\mathrm{e}}$ values in each formula are calculated from the pseudo-first and the pseudo-secondorder models, which showed that the pseudo-second-order model fits the experiment data better as the values of $q_{\mathrm{e}, \mathrm{cal}}$ are closer to the experimental results $\left(q_{\mathrm{e}, \exp }\right)$ and the $R^{2}$ of $0.977-$ 0.996 obtained from the pseudo-second-order model were much higher than that calculated from the pseudo-first-order model.

The plots in Fig. 6(d) based on the intra-particle diffusion models provide an explanation of the adsorption process, which emphasizes that adsorption in aqueous solution can be viewed as three steps, instantaneous adsorption or external surface 
Table 2 Pseudo-first-order, pseudo-second-order, and intra-particle diffusion kinetic model parameters

\begin{tabular}{|c|c|c|c|}
\hline \multirow[b]{2}{*}{ Kinetic model parameters } & \multicolumn{3}{|c|}{$T=301 \mathrm{~K}, \mathrm{pH}=4$} \\
\hline & $50 \mathrm{mg} \mathrm{L}^{-1}$ & $100 \mathrm{mg} \mathrm{L}^{-1}$ & $150 \mathrm{mg} \mathrm{L}^{-1}$ \\
\hline \multicolumn{4}{|l|}{ Pseudo-first-order model } \\
\hline$k_{1} \times 10^{-2}$ & 1.896 & 1.716 & 1.579 \\
\hline$R^{2}$ & 0.977 & 0.989 & 0.996 \\
\hline$q_{\mathrm{e}}\left(\mathrm{mg} \mathrm{g}^{-1}\right)$ & 28.6619 & 74.9686 & 115.8238 \\
\hline \multicolumn{4}{|l|}{ Pseudo-second-order model } \\
\hline$k_{2} \times 10^{-4}$ & 9.285 & 3.943 & 1.661 \\
\hline$R^{2}$ & 0.999 & 0.996 & 0.998 \\
\hline$q_{\mathrm{e}}\left(\mathrm{mg} \mathrm{g}^{-1}\right)$ & 40.5186 & 85.4021 & 144.0922 \\
\hline$q_{\mathrm{e}, \exp }\left(\mathrm{mg} \mathrm{g}^{-1}\right)$ & 37.369 & 82.731 & 127.162 \\
\hline \multicolumn{4}{|l|}{ Intra-particle diffusion } \\
\hline$k_{1}$ & 3.4362 & 9.8428 & 11.2239 \\
\hline$k_{2}$ & 1.2724 & 2.4046 & 4.5495 \\
\hline$k_{3}$ & 0.2118 & 0.2016 & 0.9545 \\
\hline
\end{tabular}

adsorption, diffusion into mesopores, and equilibrium stage. The rate of each step follows the order of $k_{1}>k_{2}>k_{3}$.

3.1.3 Adsorption isotherm studies. The adsorption isotherm is a model to investigate how the adsorbed ions are distributed over the adsorbent. From the research, Langmuir and Freundlich isotherm models are expressed as in eqn (5) and (6), respectively.

$$
\begin{aligned}
& q_{\mathrm{e}}=\frac{q_{\max } K_{\mathrm{L}} C_{\mathrm{e}}}{1+K_{\mathrm{L}} C_{\mathrm{e}}} \\
& q_{\mathrm{e}}=K_{\mathrm{F}} C_{\mathrm{e}}^{1 / n}
\end{aligned}
$$

where $C_{\mathrm{e}}$ is the equilibrium concentration of the absorbate $(\mathrm{mg}$ $\left.\mathrm{L}^{-1}\right), q_{\mathrm{e}}$ is the amount of absorbed ions at equilibrium $\left(\mathrm{mg} \mathrm{g}^{-1}\right)$. $q_{\max }$ represents the maximum adsorption capacity of the absorber $\left(\mathrm{mg} \mathrm{g}^{-1}\right) . K_{\mathrm{L}}$ and $K_{\mathrm{F}}$ are the Langmuir adsorption

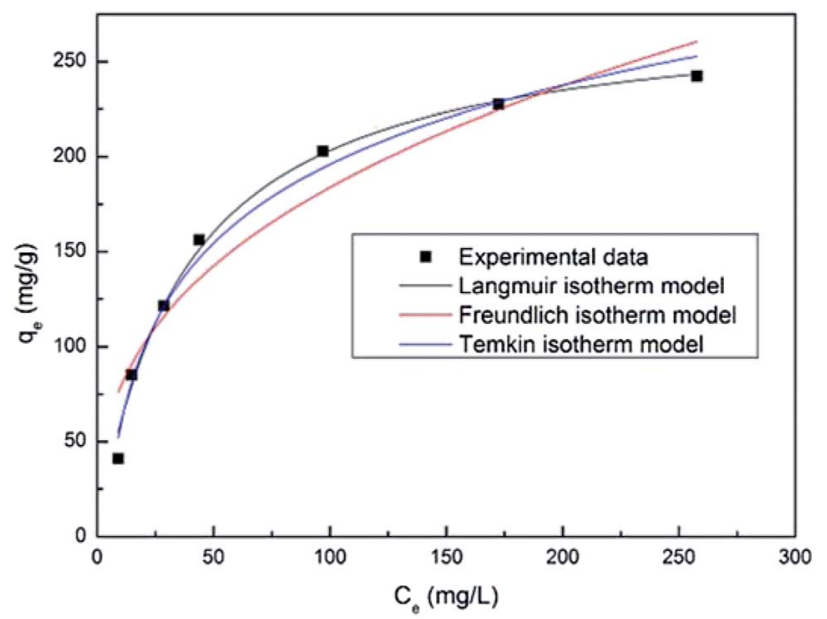

Fig. 7 Langmuir, Freundlich, and Temkin isotherms for adsorption of $\mathrm{U}(\mathrm{vI})$ ions onto PAA/CS hydrogels. (Volume, $10 \mathrm{~mL}$; absorbent dose, $0.01 \mathrm{~g}$; initial concentration, 20, 50,100,150, 200, 300, 400 and $500 \mathrm{mg} \mathrm{L}^{-1}$; $\mathrm{pH}$ value, 4.0 ; temperature, $28^{\circ} \mathrm{C}$, rotating speed, 150 rpm). constant and Freundlich constant related to the energy of adsorption $\left(\mathrm{L} \mathrm{mg}^{-1}\right) . n$ is the Freundlich constant related to the intensity.

The Temkin isotherm provides an assumption that the free energy of sorption is a function of surface coverage. The interaction of adsorbents and adsorbates has a significant effect on adsorption. The Temkin isotherm is written as:

$$
q_{\mathrm{e}}=\frac{R T}{b_{\mathrm{T}}} \ln \left(a_{\mathrm{T}} C_{\mathrm{e}}\right)
$$

where $T$ is the absolute temperature $(\mathrm{K}), R$ is the ideal gas constant $\left(8.314 \mathrm{~J} \mathrm{~mol}^{-1} \mathrm{~K}^{-1}\right), a_{\mathrm{T}}$ is the equilibrium binding constant correlating to the maximum binding energy, and $b_{\mathrm{T}}$ is the Temkin isotherm constant.

The Langmuir isotherm model states that adsorption is a simple monolayer adsorption process on a homogeneous surface, while the Freundlich isotherm model predicts the forces between ions cannot be neglected and the surface of the absorbent is not homogeneous.

Fig. 7 shows the fitting plot of the three isotherm models. As can be seen, the Langmuir isotherm model is found to be more in line with the experimental data, with the highest correlation value $\left(R^{2}=0.964\right)$ revealing a single layer adsorption process. The $K_{\mathrm{L}}$ value from the calculations of the Langmuir isotherm model is 0.02714 and the separation factor constant $\left(0.0686<R_{\mathrm{L}}\right.$ $<0.4243)$ suggests that the adsorption between the adsorbent $(\mathrm{PAA} / \mathrm{CS})$ and $\mathrm{UO}_{2}{ }^{2+}$ is favorable.

Based on the kinetic and isotherm studies, the mechanism of adsorption is probably a combination of the unpaired electrons of oxygen and nitrogen atoms with uranium ions through coordination bonds. ${ }^{23}$

3.1.4 Recovery experiments and comparison with other adsorbents. The PAA/CS hydrogel was rinsed with $0.1 \mathrm{M} \mathrm{HNO}_{3}$ solution for investigating the reusable performance of adsorbent. According to Fig. 8, the capacity of composite in absorbing radioactive ions in water only slightly declined (by $4.04 \%$ ). The outcome shows that the adsorbent in this study could be used at least five times.

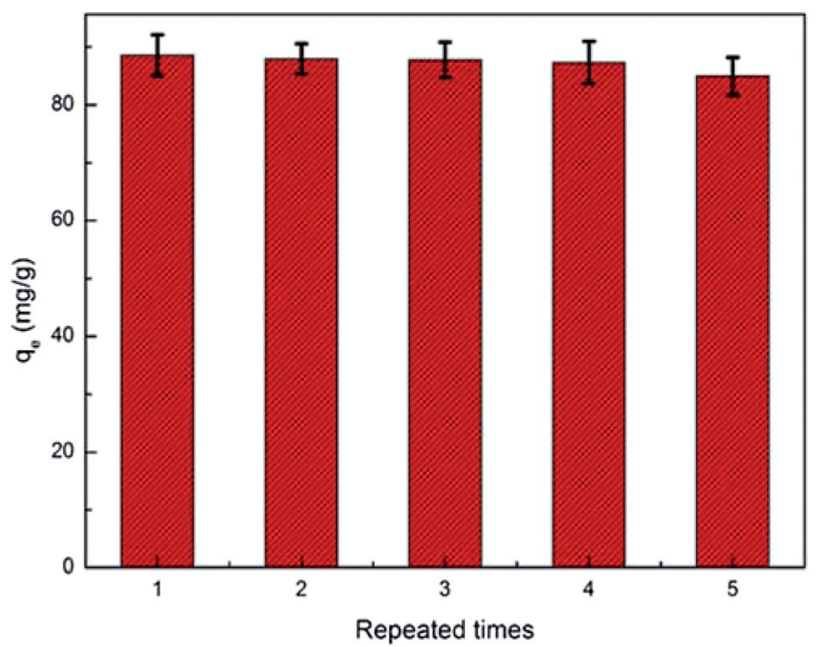

Fig. 8 Adsorption/desorption cycles (initial concentration: $100 \mathrm{mg} \mathrm{L}^{-1}$ ). 
Table 3 Comparison of adsorption capacities for $\mathrm{U}(\mathrm{VI})$ ion of various adsorbents

\begin{tabular}{lll}
\hline Absorbents & $Q_{\max }\left(\mathrm{mg} \mathrm{g}^{-1}\right)$ & References \\
\hline $\begin{array}{l}\text { Zeolite } \\
\text { Oxidized activated } \\
\text { carbon }\end{array}$ & 11.13 & 24 \\
$\begin{array}{l}\text { Carboxymethyl cellulose } \\
\begin{array}{l}\text { CMC)-grafted MWCNTs } \\
\text { Quinoline-8-ol-modified }\end{array}\end{array}$ & 25 & 25 \\
cross-linked chitosan & 112 & 26 \\
$\begin{array}{l}\text { RGO } \\
\text { SA/CMC }\end{array}$ & 218 & \\
AgOH-MWCNTs & 47 & 27 \\
PAA/CS & 101.8 & 28 \\
& 140 & 29 \\
& 289.6 & 30 \\
& & This work
\end{tabular}

As summarized in Table 3, comparison of organic, inorganic materials, and composites applied to extraction of contaminated ions in wastewater conducts that the PAA/CS hydrogel has more advantages including high efficiency of adsorption and simplicity of synthesis process than other adsorption materials.

\section{Conclusions}

A PAA/CS interpenetrating network hydrogel was prepared successfully in aqueous solution by free radical polymerization, and this hydrogel can be used in a simple and effective method for removal of the uranium from wastewater. The adsorption kinetics of PAA/CS were well described by a pseudo-secondorder kinetic model. The experimental data fit the Langmuir model well and the maximum sorption capacity of PAA/CS was $289.6 \mathrm{mg} \mathrm{g}^{-1}$. Analysis of the hydrogel structure after adsorption gave the indication that PAA/CS composites have excellent prospects in management of polluted water.

\section{Conflicts of interest}

There are no conflicts to declare.

\section{References}

1 D. Yang, S. Song, Y. Zou, X. Wang, S. Yu, T. Wen, H. Wang, T. Hayat, A. Alsaedi and X. Wang, Rational design and synthesis of monodispersed hierarchical $\mathrm{SiO}_{2}$ @layered double hydroxide nanocomposites for efficient removal of pollutants from aqueous solution, Chem. Eng. J., 2017, 323, 143-152.

2 C. Banerjee, N. Dudwadkar, S. C. Tripathi, P. M. Gandhi, V. Grover, C. P. Kaushik and A. K. Tyagi, Nano-cerium vanadate: A novel inorganic ion exchanger for removal of americium and uranium from simulated aqueous nuclear waste, J. Hazard. Mater., 2014, 280, 63-70.

3 L. Yuan, M. Sun, X. Liao, L. Y. Zhao, Z. Chai and W. Shi, Solvent extraction of $\mathrm{U}(\mathrm{vI})$ by trioctylphosphine oxide using a room-temperature ionic liquid, Sci. China: Chem., 2014, 11, 1432-1438.
4 Q. Jin, L. Su, G. Montavon, Y. Sun, Z. Chen, Z. Guo and $\mathrm{W}$. Wu, Surface complexation modeling of U(vI) adsorption on granite at ambient/elevated temperature: Experimental and XPS study, Chem. Geol., 2016, 433, 81-91.

5 H. Zhao, X. Liu, M. Yu, Z. Wang, B. Zhang, H. Ma, M. Wang and J. Li, A Study on the Degree of Amidoximation of Polyacrylonitrile Fibers and Its Effect on Their Capacity to Adsorb Uranyl Ions, Ind. Eng. Chem. Res., 2015, 54, 31013106.

6 H. Liu, R. Wang, H. Jiang, H. Gong and X. Wu, Study on adsorption characteristics of uranyl ions from aqueous solutions using zirconium hydroxide, J. Radioanal. Nucl. Chem., 2015, 308, 213-220.

7 X. Yang, J. Li, T. Wen, X. Ren, Y. Huang and X. Wang, Adsorption of naphthalene and its derivatives on magnetic graphene composites and the mechanism investigation, Colloids Surf., A, 2013, 422, 118-125.

8 D. Shao, G. Hou, J. Li, T. Wen, X. Ren and X. Wang, PANI/GO as a super adsorbent for the selective adsorption of uranium(vi), Chem. Eng. J., 2014, 255, 604-612.

9 Y. Wang, Z. Zhang, Y. Liu, X. Cao, Y. Liu and Q. Li, Adsorption of $\mathrm{U}(\mathrm{vI})$ from aqueous solution by the carboxylmesoporous carbon, Chem. Eng. J., 2012, 198-199, 246-253.

10 M. A. Dubois, J. F. Dozol, C. Nicotra, J. Serose and C. Massiani, Pyrolysis and incineration of cationic and anionic ion-exchange resins: Identification of volatile degradation compounds, J. Anal. Appl. Pyrolysis, 1995, 31, 129-140.

11 M. Carboni, C. W. Abney, K. M. L. Taylor-Pashow, J. L. ViveroEscoto and W. Lin, Uranium Sorption with Functionalized Mesoporous Carbon Materials, Ind. Eng. Chem. Res., 2013, 52, 15187-15197.

12 Z. Li, F. Chen, L. Yuan, Y. Liu, Y. Zhao, Z. Chai and W. Shi, Uranium(VI) adsorption on graphene oxide nanosheets from aqueous solutions, Chem. Eng. J., 2012, 210, 539-546.

13 S. Simsek and U. Ulusoy, Uranium and lead adsorption onto bentonite and zeolite modified with polyacrylamidoxime, $J$. Radioanal. Nucl. Chem., 2012, 292, 41-51.

14 B. Campos, J. Aguilar-Carrillo, M. Algarra, M. A. Gonçalves, E. Rodríguez-Castellón, J. C. G. E. Silva and I. Bobos, Adsorption of uranyl ions on kaolinite, montmorillonite, humic acid and composite clay material, Appl. Clay Sci., 2013, 85, 53-63.

15 S. Simsek, Adsorption properties of lignin containing bentonite-polyacrylamide composite for $\mathrm{UO}_{2}{ }^{2+}$ ions, Desalin. Water Treat., 2015, 57, 23790-23799.

$16 \mathrm{M}$. Monier and D. A. Abdel-Latif, Synthesis and characterization of ion-imprinted resin based on carboxymethylcellulose for selective removal of $\mathrm{UO}_{2}{ }^{2+}$, Carbohydr. Polym., 2013, 97, 743-752.

17 W. S. Ngah, C. S. Endud and R. Mayanar, Removal of copper(II) ions from aqueous solution onto chitosan and cross-linked chitosan beads, React. Funct. Polym., 2002, 50, 181-190.

18 Q. Wang, J. L. Mynar, M. Yoshida, E. Lee, M. Lee, K. Okuro, K. Kinbara and T. Aida, High-water-content mouldable 
hydrogels by mixing clay and a dendritic molecular binder, Nature Letters., 2010, 463, 339-343.

19 X. Yi, Z. Xu, Y. Liu, X. Guo, M. Ou and X. Xu, Highly efficient removal of uranium(vi) from wastewater by polyacrylic acid hydrogels, RSC Adv., 2017, 7, 6278-6287.

20 C. Qiao, X. Ma, J. Zhang and J. Yao, Molecular interactions in gelatin/chitosan composite films, Food Chem., 2017, 235, 4550.

21 M. Jridi, S. Hajji, H. B. Ayed, I. Lassoued, A. Mbarek, M. Kammoun, N. Souissi and M. Nasri, Physical, structural, antioxidant and antimicrobial properties of gelatin-chitosancomposite edible films, Int. J. Biol. Macromol., 2014, 67, 373-379.

22 M. Hosseini, A. Keshtkar and M. Alimoosavian, Electrospun chitosan/baker's yeast nanofibre adsorbent: preparation, characterization and application in heavy metal adsorption, Bull. Mater. Sci., 2015, 4, 1091-1100.

23 Y. Niu, D. Ying, K. Li, Y. Wang and J. Jia, Fast removal of copper ions from aqueous solution using an ecofriendly fibrous adsorbent, Chemosphere, 2016, 161, 501-509.

24 W. Zou, H. Bai, L. Zhao, K. Li and R. Han, Characterization and properties of zeolite as adsorbent for removal of uranium(vi) from solution in fixed bed column, $J$. Radioanal. Nucl. Chem., 2011, 288, 779-788.
25 C. Kütahyalı and M. Eral, Selective adsorption of uranium from aqueous solutions using activated carbon prepared from charcoal by chemical activation, Sep. Purif. Technol., 2004, 40, 109-114.

26 D. Shao, Z. Jiang, X. Wang, J. Li and Y. Meng, Plasma Induced Grafting Carboxymethyl Cellulose on Multiwalled Carbon Nanotubes for the Removal of $\mathrm{UO}_{2}{ }^{2+}$ from Aqueous Solution, J. Phys. Chem. B, 2009, 113, 860-864.

27 Y. Liu, X. Cao, Z. Le, M. Luo, W. Xu and G. Huang, PreConcentration and Determination of Trace Uranium (vI) in Environments using Ion-imprinted Chitosan Resin via Solid Phase Extraction, J. Braz. Chem. Soc., 2010, 3, 533-540.

28 S. Liu, S. Li, H. Zhang, L. Wu, L. Sum and J. Ma, Removal of uranium(vi) from aqueous solution using grapheme oxide and its amine-functionalized composite, J. Radioanal. Nucl. Chem., 2016, 309, 607-614.

29 L. Wu, X. Lin, X. Zhou and X. Luo, Removal of uranium and fluorine from wastewater by double-functional microsphere adsorbent of SA/CMC loaded with calcium and aluminum, Appl. Surf. Sci., 2016, 384, 466-479.

30 F. Zare, M. Ghaedi, A. Daneshfar, S. Agarwal, I. Tyagi, T. A. Saleh and V. K. Gupta, Efficient removal of radioactive uranium from solvent phase using $\mathrm{AgOH}-$ MWCNTs nanoparticles: Kinetic and thermodynamic study, Chem. Eng. J., 2015, 273, 296-306. 